\title{
PREENCHER O VAZIO E RASGAR O CAOS: TEATRO COMO ALIMENTO PARA A ESCOLA PÚBLICA
}

\author{
Célida Salume Mendonça (CAPES) \\ Sérgio Coelho Borges Farias (Orientador) (UFBA) ${ }^{62}$
}

Deixaste-nos mais famintos, poesia, comida estranha...

Carlos Drummond de Andrade

Difícil desejar o desconhecido, difícil ter fome do que se desconhece o sabor, do que nunca foi provado. Vi muitas vezes galerias sendo fechadas por falta de público, matérias em jornal que tentam atrair a população para freqüentar os museus de suas cidades (espaços que se impõem muitas vezes como elitizados para um público mais desfavorecido), ônibus disponibilizados para a ida ao teatro que não chegam a seu destino, por falta de quem acompanhe os alunos. Nesse contexto, sinalizo a escola pública como via de democratização do acesso à arte, como um local, muitas vezes, caótico, árido, mas igualmente fértil, e possível de despertar apetites. Parafraseando o sociólogo francês Michel Maffesoli: “(...) é a partir do caos que se opera uma recriação total” (Maffesoli, 1995, p.15).

Os alunos da rede pública de ensino de Salvador (BA), em sua grande maioria, não têm o teatro como prática presente no cotidiano escolar. Contextualizando o momento educacional vivido, seria impossível falar de teatro na escola em caráter curricular sem mencionar a má qualidade do ensino público. O que encontramos nas escolas de Salvador, em sua maioria, são professores que faltam com freqüência ${ }^{63}$, uma pedagogia tradicional que se resume na metodologia do quadro e giz, aulas expositivas centradas no professor, conteúdo livresco, repetição enfadonha de exercícios e imposição de disciplina, além de um descrédito que cresce em relação ao sistema educacional por parte de professores e alunos. Sem esquecer de mencionar a evasão escolar, a violência, alunos sem recreio, superlotação em salas de aula, inexistência de áreas de lazer e as greves que se repetem a cada ano.

Este artigo dialoga com uma experiência de ensino de teatro realizada no contexto curricular com quarenta alunos de uma turma de $4^{a}$ série ${ }^{64}$ do ensino fundamental, objeto de minha pesquisa de Doutorado desenvolvida no Programa de Pós-Graduação em Artes Cênicas da Universidade Federal da Bahia. Esses alunos frequentam uma pequena escola municipal da periferia de Salvador.

\footnotetext{
${ }^{62}$ PPGAC; Escola de Teatro;

${ }^{63}$ Com a estabilidade do emprego público, muitos professores faltam às aulas, não cumprindo a carga horária mínima. Este quadro pode ser identificado também em outros estados através de matérias veiculadas pela mídia.

${ }^{64}$ A idade dos alunos envolvidos variou em torno de 10 e 15 anos, retratando, deste modo, o nível de repetência na turma. A carga horária disponibilizada foi de 1hora/aula semanal. 
A primeira imagem oferecida por essa escola é o olhar aflito de uma mãe que aguarda ansiosa pela diretora, pois no dia anterior sua filha foi cercada e ameaçada por outras colegas ao final da aula. Sua fala revela o pensamento de defesa e proteção: "- Eu já disse pra minha filha... a gente nasce só e tem que conviver só!” E em relação à represália enfrentada pela aluna, a fala de uma professora alimenta mais ainda este pensamento: “- Assim nasce o menor infrator!" Outra professora aquece a discussão lembrando que recentemente uma aluna teve o rosto cortado por uma navalha na escola vizinha. Enquanto aguardo meu horário para entrar na sala e me apresentar aos alunos, a mãe permanece na Direção e a professora da turma em questão vem acompanhar a conversa. Os alunos ficam a sós na sala e logo se desencadeia uma briga que termina com socos e sangue.

Em conversa com a professora, fico sabendo que no ano anterior, por determinação da direção, os alunos não tinham recreio, no intuito de minimizar a violência. Além da violência do próprio bairro retratada no depoimento das crianças: "Aqui no bairro tá tendo tiroteio no largo e já mataram dois. Ontem tinha sete viaturas aí. Pegaram um menino daqui da escola ali em cima e deram um baculejo nele. A polícia disse que depois de oito horas não quer ver nenhum menino lá em cima”. A situação de pobreza da maioria das famílias obriga ainda as crianças a trabalharem no turno oposto as aulas, e muitas vezes, até nos finais de semana. Uma das alunas afirma trabalhar todas as tardes de diarista, enquanto outros valam carros. Há um estranho contraste entre a suposta infância, período em que se encontram a maioria das crianças que frequentam o ensino fundamental e o amadurecimento precoce a que são submetidos.

Durante o ano de 2007, esses alunos experimentaram o sabor de uma aula de teatro, dentro de todas as dificuldades apresentadas pela rotina de uma escola pública. A proposta inicial seria desenvolver durante um semestre, um processo criativo em teatro partindo do eixo temático da escola neste ano: IDENTIDADE. O percurso seria alimentado por diferentes estímulos como histórias de familiares recontadas pelos alunos, identidade de origem, noção de pertencimento ao bairro, imagens, músicas, instrumentos musicais ${ }^{65}$, objetos, entre outros. Conteúdos como o bairro, seu processo de modificação, a vida cultural, o trabalho, as formas de lazer e as relações centro e periferia, são sugeridos pelas Diretrizes curriculares para a inclusão da história e cultura afro-brasileira e africana no Sistema Municipal de Ensino de Salvador (2005).

$\mathrm{O}$ desenvolvimento de um percurso teatral na escola pública não esbarra apenas em questões estruturais como falta de espaço físico ou número excessivo de alunos. Rasgar o caos implica em trabalhar com alunos que não se olham, não se tocam, que não saem de suas carteiras, e muitas vezes, nunca realizaram atividades em grupo. Como desenvolver uma experiência que propõe um universo desconhecido, uma nova maneira de se relacionar com o espaço e com o outro?

\footnotetext{
${ }^{65} \mathrm{O}$ pau de chuva, a calimba e o atabaque são utilizados nas aulas de teatro tanto em sua função usual nos exercícios e improvisações, como no jogo teatral sendo transformado, e também com o objetivo de sinalizar o início e fim das cenas criadas pelos alunos. 
Segundo Carmela Soares (2003), “(...) o 'espaço vazio' aberto pelo jogo em sala de aula está sujeito ao imprevisto, ao caos, ao desejo do grupo, à força e às pulsões positivas e negativas do coletivo". Assim, ensinar teatro na escola implica em rasgar esse caos, em estar atento a cada atitude, em redimensionar cada ação, em planejar diferentes possibilidades de abordar o tema gerador, num processo que não perca de vista uma perspectiva lúdica. O significado da aula para esses alunos depende de um planejamento criativo. Produzir ordem a partir do caos faz com que a experiência teatral seja ainda mais gratificante e desafiadora.

A FOME reconhecida no espaço escolar não se refere à ausência de um único alimento nem simplesmente ao corre corre diante da hora da merenda. É fome de imagens, fome de serem bem tratados, fome de infância, fome de aulas planejadas, de reconhecimento, de socialização, de visibilidade, de valorização...

Eu gostei muito pelo esforço da professora pelos meus colegas e mostrou seu interesse seu amor pelos meus colegas e por isso eu gostei. Pra mim teatro é uma atividade que trabalha com a nossa mente trabalha com o nosso corpo faz a gente ser feliz por isso gostei peço obrigado a professora por me ensinar a ser feliz e uma pessoa forte. (Registro de uma aluna da turma de $4^{\text {a }}$ série)

E até mesmo, fome de aulas, considerando a freqüente falta de professores nas escolas públicas. E, sobretudo, fome de arte, fome de TEATRO.

No primeiro dia de aula, com a ajuda de todos, colocamos as carteiras nos cantos da sala por etapas, quando é possível constatar que não restava muito espaço para eles se deslocarem. Esse mínimo movimento de desorganização da rigidez desse espaço já delatava uma nova relação, o "estar junto" - já não haviam mais carteiras separando aqueles corpos. No próximo encontro retiramos todas as carteiras e estendemos no chão da sala uma lona que entra nesse novo espaço suspensa, carregada por um grupo de alunos. Ao se lançarem sobre a lona a euforia é geral. Eles viram estrelas, lutam capoeira, giram, pulam, fazem piruetas, correm e se jogam no chão, dão rasteiras nos colegas, rolam sobre eles, arrastam outros e nada consegue detê-los. Proponho uma atividade que inicia, mas em questão de minutos se dilui formando focos de briga.

(....) estética no seu sentido mais simples: vibrar em comum, sentir em uníssono, experimentar coletivamente, tudo o que permite a cada um, movido pelo ideal comunitário, de sentir-se daqui e em casa neste mundo. Assim, o laço social é cada vez mais dominado pelos afetos, constituído por um estranho e vigoroso sentimento de pertença. (MAFFESSOLI, 2005, p.08)

A lona entra aqui como possibilidade de transformar, transgredir, redimensionar esse espaço, e, acima de tudo, retomar esse laço social e afetivo. É evidente que os alunos não reconhecem nesse novo ambiente uma área 
delimitada para a prática teatral, e sim um lugar onde a relação corpo/espaço é diferenciada do que lhes é cotidianamente oferecido; precisam, portanto, de um tempo para aprender a ocupar esse espaço que foge totalmente do modelo original.

Nas aulas seguintes são realizadas atividades de deslocamento e ocupação do espaço, congelamento, exercícios preparatórios, danças, jogos teatrais com diferentes estímulos como tecidos, imagens e objetos. Na maioria das propostas, após a orientação inicial, eu participava junto com os alunos, o que causava em alguns um olhar de estranhamento e em outros um doce sorriso no rosto. A entrada do professor no jogo é defendida por Flávio Desgranges (2006):

A sua participação, entrando vez ou outra no jogo, intensifica a relação com os demais integrantes do grupo, possibilitando que estes percebam e se contagiem com o seu prazer em participar das atividades. (...) Uma relação diferente se estabelece, pois desmistifica a figura do coordenador no grupo, aproximando-o dos demais integrantes, que se sentem mais à vontade para jogar. (DESGRANGES, 2006, p.98)

nesse primeiro momento, o referencial Identidade passa a ser introduzido nas aulas. Observando a dispersão inicial do grupo e o próprio movimento da turma, penso em levar para a aula algo que desperte a atenção deles, que gere curiosidade em torno do subtema: o corpo como identidade. Fui para a escola nesse dia usando um terceiro olho ${ }^{66}$. Logo ao chegar me perguntaram o que era aquilo na minha testa e assim já fomos entrando no horizonte da aula. Falei de nossa identidade de origem, constituída pelos nossos antepassados e que este terceiro olho, que evidenciava o corpo como expressão estética, estava relacionado a meu avô paterno nascido na Síria. Contei então, através de uma estória, o que imaginava quando era criança: que meu avô havia trazido um baú com roupas de odaliscas quando veio para o Brasil fugido da guerra, e que estas, seriam herdadas por mim. Depois os alunos receberam como tarefa trazer histórias contadas por seus familiares para serem recontadas por eles.

Em Pedagogia do Teatro: provocação e dialogismo (2006) Flávio Desgranges recupera o pensamento do educador francês Philippe Meirieu ao ressaltar que quem sabe ouvir histórias, exercita também a capacidade de criar e contar histórias. Prossegui, falando que, assim como eu, a professora deles também era de descendência árabe. E que eles também possuíam sua identidade refletida no jeito de arrumar os cabelos, de se enfeitar, nas danças, no gosto musical, na capoeira, nos costumes mantidos ou ressignificados que fazem parte da construção de diferentes culturas. Ouvimos músicas relacionadas à minha ancestralidade e outras relacionadas à deles. Depois todos dançaram pelo espaço acompanhando os ritmos de diferentes culturas, e ao sinal de uma palma congelavam, formando diferentes imagens.

${ }^{66} \mathrm{O}$ Terceiro Olho refere-se a intuição e a consciência, consiste em um adorno usado na testa pelas dançarinas de Dança do Ventre relacionado a cultura de países do Oriente Médio. 12 
Nas propostas instauradas nessa primeira etapa, os alunos não permaneciam envolvidos por muito tempo na mesma atividade. Observava-se em alguns momentos maior participação e menor rejeição, mas tudo que era proposto levava muito tempo para iniciar de forma efetiva. Muitas vezes, os alunos saíam da atividade para provocar os colegas, desencadeando brigas. Em uma das aulas, diante da orientação de um jogo corporal construído com seus nomes, eles pareciam encantados, mas com a formação dos grupos, recuavam. Alguns demonstravam interesse, mas se negavam a fazer parte dos grupos estabelecidos. Não demorou muito tempo para a suspeita se confirmar: os alunos nunca haviam trabalhado em grupo (grifo meu). Um dos alunos enfatiza o problema: "O pessoal do lado de cá não se mistura com o do lado de lá, Pró."

Segundo Tomaz Tadeu da Silva (2007): "Dividir o mundo social entre 'nós e 'eles' significa classificar". Dividir e classificar significa ainda hierarquizar. Em algumas situações os alunos justificavam a distância estabelecida com falas de discriminação e preconceito. Suas vozes reafirmavam a necessidade já antecipada de trabalhar a socialização através do eixo Identidade. A socialização como um processo de identificação, de construção de identidade, de relação e de pertencimento a esse grupo. Conversamos sobre uma identidade que se constrói na relação com o outro, na mistura de diferentes identificações positivas e negativas durante nossa vida.

Em Identidade e Diferença: a perspectiva dos estudos culturais Tomaz Tadeu aponta a questão do outro e da diferença como um problema pedagógico e curricular. Mesmo quando ignorado ou reprimido, a volta do outro, do diferente, é inevitável, explodindo em conflitos, hostilidades e até mesmo violência: "O outro é o outro gênero, o outro é a cor diferente, o outro é a sexualidade, o outro é a outra raça, o outro é a outra nacionalidade, o outro é o corpo diferente" (Silva, 2007, p.97). Respeitar a diferença significa deixar que o outro seja diferente, acolher o outro como outro. Esse outro é permeado também por sua identidade de origem e pelo lugar onde mora.

Em outro encontro coloco no quadro as seguintes questões: "Quem sou eu... de onde vim... filho de quem... o lugar onde moro...”. Peço silêncio e olhos fechados. Anuncio que a fala/poema de Wally Salomão que estarão ouvindo cantada pelo próprio poeta estará relacionada às perguntas que serão feitas a eles na seqüência.

"Experimentar o experimental, experimentar o experimental... a fala da favela.

O nódulo decisivo nunca deixou de ser o ânimo de plasmar uma linguagem convite para uma viagem. E agora? Quer dizer, o que é que eu sou?

Meu nome é Wally Salomão, um nome árabe. Wally Dias Salomão. Nasci numa pequena cidade da caatinga baiana, do sertão baiano. Filho de pai árabe e uma sertaneja baiana.

A memória é uma ilha de edição. A memória é uma ilha de edição.

Nasci sob um teto sossegado, meu sonho era um pequenino sonho meu. $\mathrm{Na}$ ciência dos cuidados fui treinado. Agora, entre o meu ser e o ser alheio, a linha de fronteira se rompeu... câmara de éter. 
Eu tenho o pé no chão. Porque sou de virgem. Mas a cabeça, gosto que avoe...."

(WALLY SALOMÃO: "O Rappa - O Silêncio Q Precede O Esporro", 2003)

Quando a fala finaliza pergunto a eles sobre o que ouviram. Suas vozes se sobrepõem, um dos alunos diz que Wally é filho de árabe e outro diz que ele também nasceu na Bahia. Falo que estaremos fazendo o mesmo a partir das questões colocadas no quadro, mas que eles serão filmados enquanto falam, pois estas imagens serão utilizadas posteriormente no nosso percurso teatral. A filmagem dos depoimentos tem um efeito mágico e inesperado sobre os alunos. Todos se contagiam com as primeiras falas, mas ao mesmo tempo que querem participar, a curiosidade maior está em ver a imagem de quem está sendo filmado na tela da filmadora. Durante as falas quando um aluno fica tímido e emudece, um dos alunos "do lado de lá" atravessa a sala e toma a iniciativa de entrevistá-lo, transformando a caneta em microfone e elaborando novas perguntas. As crianças seguem então falando com segurança e cheias de propriedade diante da câmera. $\mathrm{O}$ evento passa a ser a filmagem.

E sem dúvida o nosso tempo... prefere a imagem à coisa, a cópia ao original, a representação à realidade, a aparência ao ser... Ele considera que a ilusão é sagrada, e a verdade é profana. E mais: a seus olhos o sagrado aumenta à medida que a verdade decresce e a ilusão cresce, a tal ponto que, para ele, o cúmulo da ilusão fica sendo o cúmulo do sagrado. (FEUERBACH apud DEBORD, 1997, p.13)

$\mathrm{Na}$ aula seguinte, a exibição dessas imagens acabou por mobilizar toda a escola. Em poucos minutos vários alunos das outras turmas estavam espremendo-se na porta pra ver os colegas na televisão, enquanto que os alunos da $4^{\text {a }}$ série saboreavam suas próprias imagens. Em Magia e Técnica, Arte e Política (1993), Walter Benjamin fala sobre a enorme atração que a idéia de se fazer reproduzir pela câmara exerce: "(...) a idéia de uma difusão em massa da sua própria figura, de sua própria voz, faz empalidecer a glória do artista teatral" (Benjamin, 1993, p.182). Essas simples imagens hipnotizam e dão voz e visibilidade a esses alunos.

No decorrer do processo os alunos construíram em grupos uma seqüência de cenas que revelaram suas histórias, suas escolhas, seus desejos, suas opções de lazer e cuidados com o bairro. No transcorrer das aulas uma metamorfose contínua foi se operando sob nossos olhos: jogos de contato foram realizados na área externa, improvisações em grupo puderam ser elaboradas e apresentadas, as brigas diminuíram, demonstrações de afeto e sorrisos começaram a ser mais frequientes. O impacto causado pelo registro fílmico de algumas aulas, não minimizou o prazer desfrutado por muitos no percurso desenvolvido nas aulas de teatro. O processo enfrentou ainda um longo período de greve no momento em que as relações começavam a se estabelecer. Apesar da previsão inicial de 
um semestre, com a greve, observou-se a necessidade de estender as aulas até o final do ano letivo.

Superando o imaginário caótico instalado inicialmente, a escola transforma-se em espaço lúdico, de relação, de saber e de democratização do acesso à estética teatral. A epígrafe inicial que abre o texto pode ser aqui relida ao sugerir metaforicamente o que representa para esses alunos provar Teatro, ter o gosto pelo teatro despertado, um gosto que permanece no corpo, no prazer que foi provocado, um gosto de quero mais!

Eu gostei muito da aula de teatro eu fui aprendendo muito e fui desenvolvendo o que eu não sabia. Eu fiz muitas coisas apresentei duas vezes e eu gostei muito mas agora eu não queria que terminasse mas já chegou o final do ano e é uma pena eu não poder continuar na aula de teatro. (Registro de uma aluna da turma de $4^{\mathrm{a}}$ série)

\section{Referências}

BENJAMIN, Walter. Magia e técnica, arte e política: ensaios sobre literatura e história da cultura. São Paulo, Brasiliense, 1993.

DEBORD, Guy. A sociedade do espetáculo. Rio de Janeiro: Contraponto, 1997. DESGRANGES, Flávio. A Pedagogia do Espectador. São Paulo: Hucitec, 2003.

Pedagogia do teatro: provocação e dialogismo. São Paulo: Editora Hucitec: Edições Mandacaru, 2006.

MAFFESOLI, Michel. O mistério da conjunção: ensaios sobre comunicação corpo e socialidade. Trad. Juremir Machado da Silva. Porto Alegre: Sulina, 2005.

A contemplação do mundo. Porto Alegre: Artes e Ofícios Ed., 1995.

SANTOS, Gedalva da Paz (coord.) Diretrizes curriculares para a inclusão da história e cultura afro-brasileira e africana no Sistema Municipal de Ensino de Salvador. Prefeitura Municipal de Salvador, Secretaria Municipal da Educação e Cultura. Salvador, 2005.

SILVA, Tomaz Tadeu (org.) Identidade e diferença: a perspectiva dos estudos culturais. Petrópolis, RJ: Vozes, 2007.

SOARES, Carmela Correa. Pedagogia do Jogo Teatral: uma poética do efêmero - $O$ ensino do teatro na escola pública. Rio de Janeiro, 2003. f. Dissertação (Mestrado) - Programa de Pós-Graduação em Teatro do Centro de Letras e Artes da UNIRIO.

"Bahia tem piores índices de escolaridade de todo o Brasil". A Tarde, Salvador, BA, 14 mar. 2007. 